\title{
The Use of Interactive Virtual BIM to Boost Virtual Tourism in Heritage Sites, Historic Jeddah
}

\author{
Ahmad Baik
}

Citation: Baik, A. The Use of Interactive Virtual BIM to Boost Virtual Tourism in Heritage Sites, Historic Jeddah. ISPRS Int. J. Geo-Inf. 2021, 10, 577. https://doi.org/ 10.3390/ijgi10090577

Academic Editors: Eva Savina Malinverni and Roberto Pierdicca

Received: 19 July 2021

Accepted: 20 August 2021

Published: 26 August 2021

Publisher's Note: MDPI stays neutral with regard to jurisdictional claims in published maps and institutional affiliations.

Copyright: (c) 2021 by the author Licensee MDPI, Basel, Switzerland. This article is an open access article distributed under the terms and conditions of the Creative Commons Attribution (CC BY) license (https:/ / creativecommons.org/licenses/by/ $4.0 /)$.
Geomatics Department, Faculty of Architecture and Planning, King Abdulaziz University (KAU), Jeddah 21589, Saudi Arabia; abaik@kau.edu.sa; Tel.: +966-0-505663599

\begin{abstract}
Today, moving from a two-dimensional environment to a more advanced interactive threedimensional (3D) environment in the industries of architecture, engineering, and construction has become one of the most significant topics of interest. This is due to several primary advantages that the 3D environment can offer. Building information modeling (BIM) can be used as a highly advanced system to present a desired reality in a 3D interactive environment accompanied with 3D reality captured data, such as the point cloud data. As such, these 3D environments can be employed for more advanced uses, such as virtual reality and augmented reality technologies (VR and AR). Recently, BIM has been employed in the context of heritage (known as HBIM, or Heritage Building Information Modeling) for different purposes, such as to provide as-built information with the ability to interact with the end user and uploading information (e.g., historical photographs, documents about materials, or any past restoration projects) into the BIM model. This research will focus on providing an interactive rich virtual 3D model for heritage management. This virtual environment can be employed in cultural tourism and used for the abovementioned purposes. The research project has been adopted in the case of the Zainal Historical House (Bayt Zainal) located in the Historic District of Jeddah, Saudi Arabia. This house is described as one of the significant historical buildings in the historic district. The key aim for selecting this case study is to bridge the gap in architectural knowledge regarding these heritage buildings and their hybrid structural systems (i.e., integration of steel or concrete with the traditional "Mangbi" stone technique).
\end{abstract}

Keywords: BIM; HBIM; AR; VR; CRP; 3D documentation; point cloud; laser scanning

\section{Introduction}

Technological improvements have made life easier and changed how people interact with each other and their environment. Due to technological advancements such as virtual environments, people can enjoy the experience of a place without having to physically visit it.

Virtual and augmented reality technology (VR \& VA) has the ability to change people's perceptions of the world. Virtual reality technology has many applications, including its use in the preservation of historical buildings for generations to come. The use of interactive 3D graphics in VR has also enabled this technology to be applied in designing, digital painting, and photo editing software, which can exhibit an architect, designer, or engineer's perceptions. It has the capacity to preserve traditional designs such as artwork from damage which may occur as a result of frequent traffic from visitors. In present day, the Kingdom of Saudi Arabia has been applying huge efforts in the tourism sector, one of the supposed cornerstones of "Vision 2030", a national program targeting the transition from an oil-dependent to a comprehensive and multi-source economy. The country is therefore developing many of its important historical sites, with some being Al Ula, Madain Saleh, Ad-Dariyah (Figure 1), Historic Jeddah, and others. Several of these sites are listed on the UNESCO world heritage list, making them priorities for preservation and restoration and, hence, tourism. 


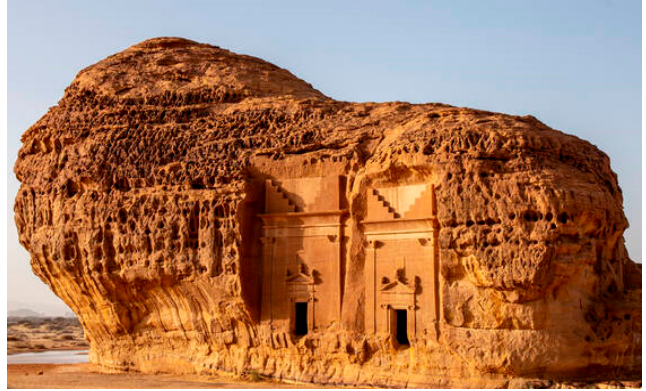

(a)

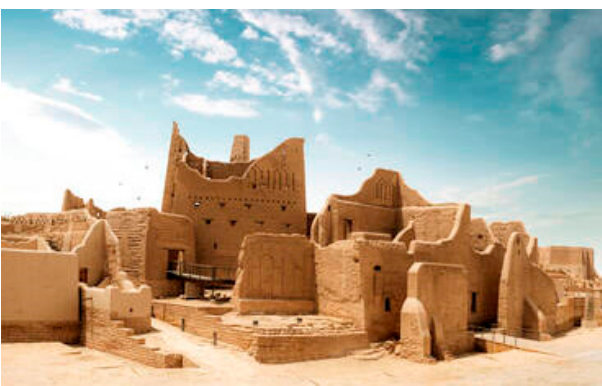

(b)

Figure 1. (a) Al-Hijr archaeological site (Madain Saleh) and (b) At-Turaif District in ad-Dir'iyah.

\subsection{Historic Jeddah: UNESCO World Heritage Site}

Historic Jeddah is considered to be one of the most important heritage sites in the kingdom. The city is well-known as "the gate to Makkah", which is considered the most valuable city in the Islamic world. Jeddah is situated on the western side of Saudi Arabia. Its historic district has a long history, and there are several heritage sites and buildings. According to the Saudi SCTA [1], the number of buildings of this heritage is approximately 1442 heritage sites. These buildings are said to have been constructed between 300 and 1200 years ago, with some being Nassif House, Baeshen House, Sharbatly House, Zainal House (Figure 2), and many more. Since 2014, Historic Jeddah has been listed as one of the UNESCO world heritage sites.

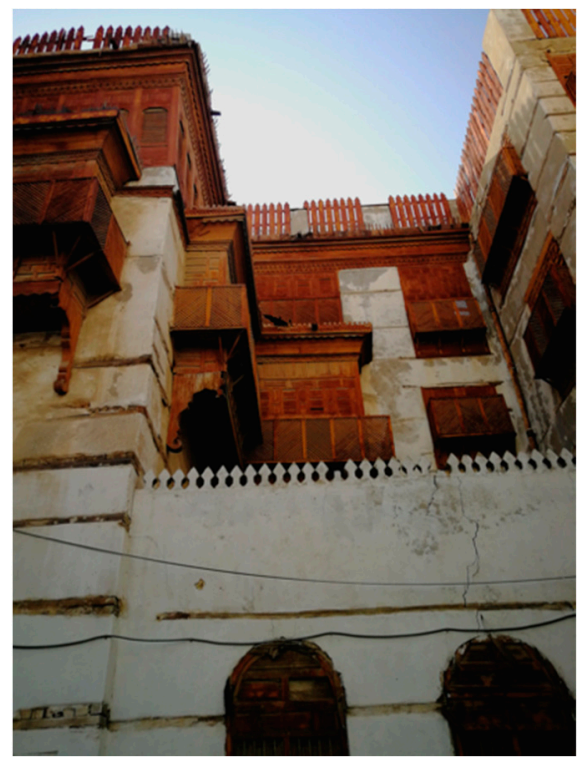

(a)

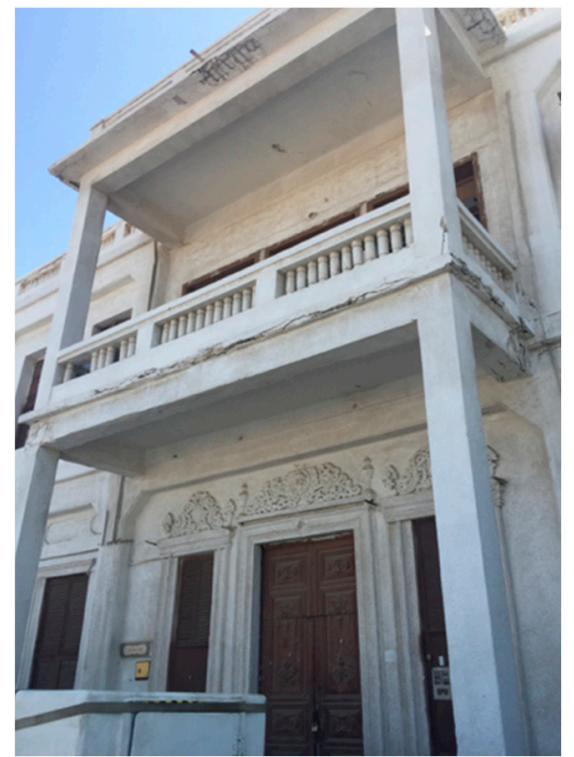

(b)

Figure 2. Historic buildings: (a) Baeshen House and (b) Zainal House.

\subsection{Challenges of Heritage Sites}

The most significant issues faced by heritage sites and monuments in the world are natural damage and degradation over time [2]. A majority of heritage sites face issues with tourism (physical visits), mainly sites that are listed as UNESCO world heritage sites, which are possibly under greater threat due to their world cultural heritage status. These sites attract a large number of tourists, much to their detriment. It can be clearly noted in one example how the impact of tourism has affected Alhambra's floors in Granada. As such, heritage restoration, as well as preservation efforts, are necessary to account for human and environmental issues occurring at these monuments and sites. 


\subsection{Research Aim}

A high level of entertainment can be offered via AR and the VR reality environment, which are rich in multimedia content. The integration of digital information and the geometry within the Heritage Building Information Modeling (HBIM), AR, and VR can provide a novel way to realize, preserve, and reuse cultural heritage sites [3].

This research aims to provide historical sites with an interactive and rich virtual 3D model for heritage management. The interactive 3D model would be based on 3D point cloud data. This data can be provided via photogrammetry or terrestrial LiDAR techniques. The Heritage BIM model would then be used as a base model for virtual environment applications to be employed for cultural tourism purposes and to be remotely reviewed, with the ability to interact with the end user and upload information (e.g., historical photographs, documents about materials, or any past restoration projects) into the BIM model.

\section{Literature Review}

\subsection{The Implementation of BIM in Heritage}

The main concept behind using BIM is to provide higher efficiency in each sector of the building industry from the conceptual design until demolition by focusing on energy, economic, and structural analysis, as well as the scheduling of the works in addition to these new designs [4]. Currently, BIM is employed in different contexts and for different purposes in the architecture, engineering, and construction (AEC) industries. Therefore, each engineering sector has their own explanation of BIM. BIM was defined by the US National BIM Standard Project Committee (NBIMS-US) as "a digital representation of physical and functional characteristics of a facility", which can thus be presented as "a shared knowledge resource for information about a facility forming a reliable basis for decisions during its life-cycle", and this can be outlined as "existing from earliest conception to demolition ..." "[5]. Moreover, Murphy [6] outlined BIM as "the assembling of parametric objects which represent building components within a virtual environment", and this can be used to model and represent the entire building. The "parametric objects" are described according to parameters, some of which are user-defined and others relate to the position in a 3D environment relative to other "shape objects". Through the BIM databases, architectural objects such as doors, walls, and windows are related to one another and have their own properties (for instance, materials and dimensions). Furthermore, in the BIM database, all the architectural objects are related to the whole project, as additionally, the relationship between the project's objects allows the database to modify and update the chosen objects simultaneously for all of the project's stakeholders.

Employing BIM in the heritage project fields has been presented as a novel technique over the past decade. This can be considered the primary stage toward the use of the BIM workflow for reconstruction as well as retrofitting tasks [7]. This new technique is termed Heritage BIM, where the flow diagram of the different processes and professional figures involved in the project can be summarized as shown in Figure 3. Moreover, according to A. Baik [8], Heritage BIM has been defined as "a digital representation of the current situation of the physical and functional characteristics of heritage buildings with respect to any modifications, restoration and maintenance during the heritage building lifecycle." The Heritage BIM technique has been employed in several projects in European countries, such as in [6,9-14]. The core subject of these pieces of research and projects was to deliver intelligent information [10], as well as to offer "as-built" digital 3D models [15] to be used for different purposes. For example, they could be used in management documentation and for conservation. Almost all of these studies used point cloud data, which was generated from close-range photogrammetry (CRP) and terrestrial laser scanning (TLS) [16-18]. This point cloud was then used as the basic phase for data capturing. This phase is generally known as "Scan to BIM" [19] or, in the case of heritage projects, "Scan to HBIM" [20-22]. Furthermore, based on the scanned surface, each of these points has " $\mathrm{x}, \mathrm{y}$, and $\mathrm{z}$ coordinates". According to Murphy [6], the "laser ranger is directed towards an object by reflective surfaces that 
are encoded", and hence, "their angular orientation can be determined for each range measurement." According to Thomson and Boehm [23], point cloud data can be designated to be $\operatorname{LoD} 0$ (the absolute minimal level of detail), from which more data-rich abstractions can be shaped in order to be modeled to higher levels of detail (i.e., LoD 400 or 500).

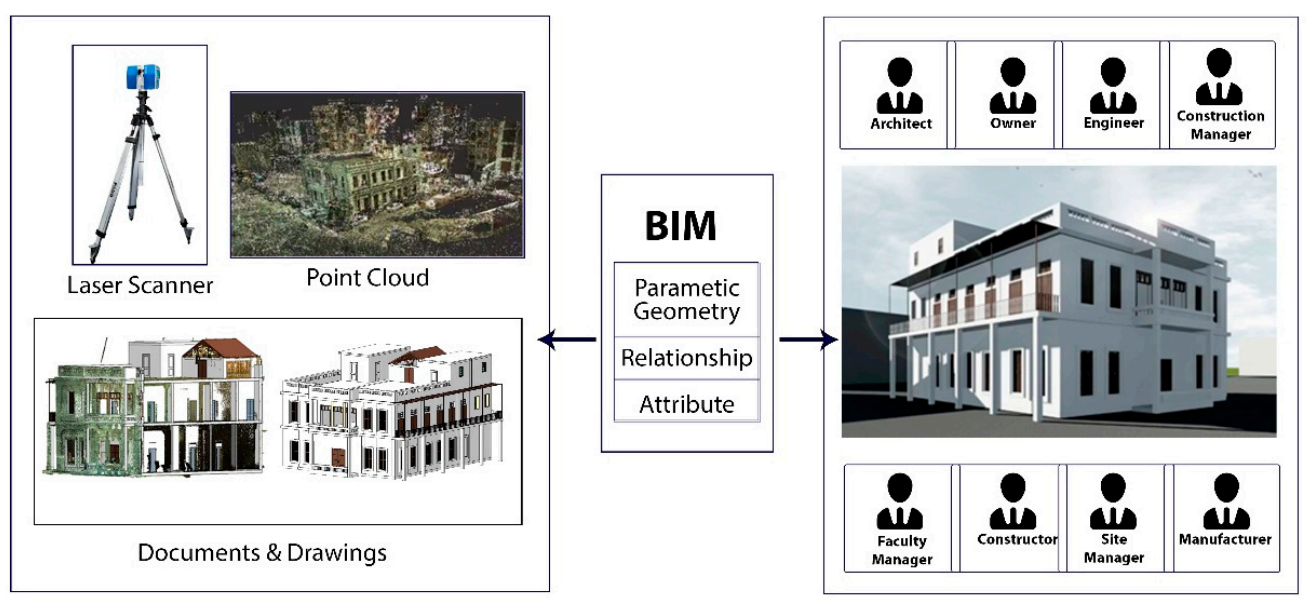

Figure 3. Working parameters of HBIM.

\subsection{The Difference between Virtual, Augmented, and Mixed Realities}

There are many differences between virtual reality (VR) and augmented reality (AR). In $\mathrm{VR}$, a complete imaginary $3 \mathrm{D}$ environment can be created, while AR superimposes the 3D digital information over the existing 3D environment [17]. Currently, it can be noted that the visualization techniques of using VR and AR have fewer applications in the architecture, engineering, and construction (AEC) sector compared with the gaming, manufacturing, medical operation, and military sectors, but they are gaining momentum in the infrastructure of buildings as well as in all phases of the building life cycle $[17,18]$.

Moreover, extended reality (XR) can be described as a holistic expression that covers the full spectrum of reality. These 3D environments, specifically virtual reality (VR), augmented reality (AR), and mixed reality (MR), are applied to effectively integrate the line separating reality and fantasy, forcing the limits of the user's imagination as well as allowing entraining of any experience imaginable. Each of the three realities accomplishes this differently. Figure 4 shows how the human brain processes images to be seen in the virtual environment. With a keen understanding of how VR emerges via having a head-mounted display (HMD) over one's head (including headphones), two main sensory inputs (sight and sound) are being taken over. Because of this, VR environments typically block out the real world. In fact, VR can be described as a platform that allows an ease of understanding of different sites without visiting the actual place using computer-generated programs (CGPs). According to Ramsey [24], "Virtual reality was used for the first time in 1994 by heritage museum during a demonstration that provided a walk-through of Dudley Castle in England as it was in 1550". Thus, this technology permits people to travel to different places, relax, and learn about heritage places and other cultures. Hence, virtual reality technology has dramatically revolutionized the tourism industry and brought past and lost experiences back to life [19]. 


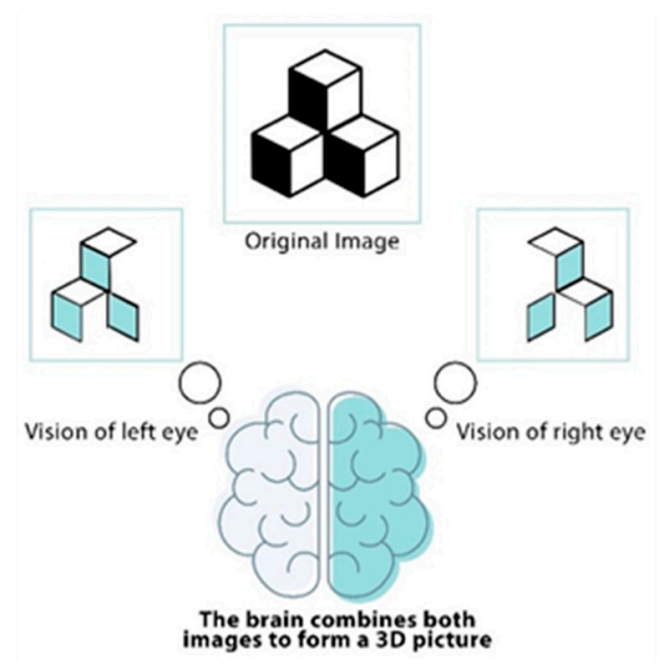

Figure 4. How our brains process images.

On the other hand, AR can be described as a method to represent the real world explicitly (or by a camera that produces a picture of the actual surrounding world) and then "augmenting" that reality through a visual input created within a computer. In fact, AR uses the concept of overlapping and integrating via a transparent screen, which displays pictures and data in an existing environment [20]. Moreover, both VR and AR, despite having similar device structures, achieve two very different things in two entirely different methods. The VR replaces reality and sends the user to another place. Aside from that, AR is combined with reality, adding data on top of what the user is already seeing. Additionally, the virtual edition is generated into the real world via creating images, audio, or video. AR differs from VR in that it adds up objects or new scenes to the digital real-world projection instead of building every $3 \mathrm{D}$ digital element of the visual experience from the beginning. [21]. Furthermore, information, instructional data, emotional artifacts, and characters are projected over AR's real-world view, adding a layer into the actual real world. In fact, AR is often used with the smaller devices of VR (e.g., a smartphone or tablet). One hugely successful app (Pokémon GO), an example of AR application, includes virtual characters extended into the real world and seen over the smartphone camera. Another example, which is more realistic for the architecture profession, would be an engineer demonstrating a construction worker remotely constructing a particular wall specification [19]. Examples of this technology include Apple's ARkit and Google's ARcore. these applications can present the physical world in a 3D digital environment, with building a digital layer on top of this reality, and can even cast digital shadows on physical objects, such as buildings, and mountains. Additionally, AR gives no communication with the augmented digital environment, while mixed reality provides this kind of interaction (Figure 5: Reality-verticality continuum).

\section{REALITY-VIRTUALITY CONTINUUM}

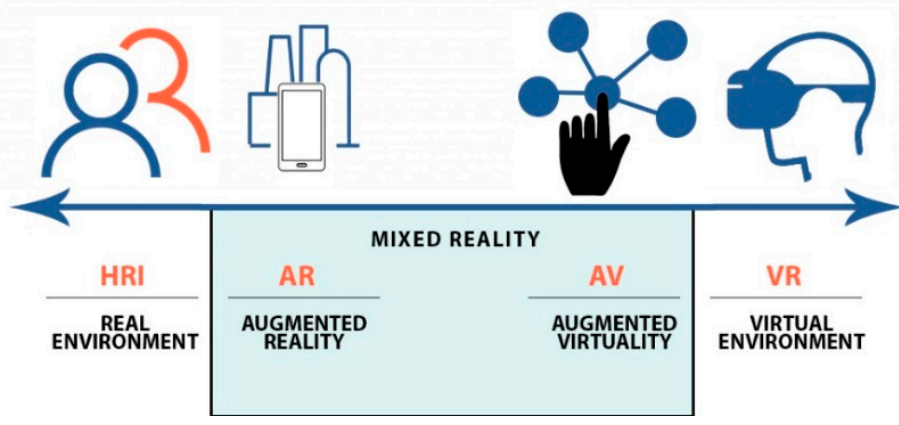

Figure 5. Reality-verticality continuum. 
Mixed reality (MR) involves the real world and inserts computer-generated content in order to communicate a real-world experience. Furthermore, this holds the ability to capture as well as link fully generated virtual worlds over real-world objects. This can make it the only technology capable of integrating analog and digital realities. Aside from that, all three of these platforms (VR, AR, and MR) are also applied to deeply interactive or digital environments that bring value into the virtual space discussion. Regarding the architectural sense, the critical advantage of being in a true-scale virtual version of a building project is that it supports the expected user to understand, communicate, and critique a design in the most natural way when it is still being developed and constructed in the real world. Additionally, for these different realities in a completely virtual environment, VR appears to be the most suitable technique in order to access the sense of immersion or the sensation of "being". Furthermore, in the architectural field, many projects rely on understanding as well as producing new environments, therefore requiring complete virtual immersion when presented to clients, peers, or students. However, VR can be seen as bringing design imagination to most of the architectural process. In fact, AR could provide more specific abilities in order to overcome the visualizations of transformations and projects with real-world features. Moreover, AR can be a perfect fit for projects that need visualizations of enhancements and changes to existing scenarios. As AR cannot reach the level of virtual immersion that VR can. It is more suitable for projects that need a layer of virtual immersion attached to spaces existing in real life. When VR shuts a user off from the physical world through controlling their vision, it can be used in order to envision nearly any space regardless of whether or not there is architectural space in the present. Therefore, this makes it more diversely suitable to the entire work in the architectural field.

\subsection{BIM-Based and Applications of VR and AR}

It can be agreed that the technologies of VR and AR are not typically stand-alone tools; they are used in conjunction with other technologies like geographic information systems (GISs), the Internet of things (IoT), and cloud computing [22]. For example, the integration of these technologies can be shown in the visualization of prefabrication or construction phases through VR using real-time data captured through the IoT and cloud computing [18].

Constructability investigation utilizing BIM has not been successful due to the lack of communication between stakeholders participating from different geographical places [18]. In the virtual design and construction field, utilizing VR empowers users to digitally explore via a digital 3D BIM model, which assists with bringing together all the stakeholders from remote locations. Through walking in the 3D BIM with a schedule model-described as 4D-BIM in a VR environment-constructability analysis contributes to the productive and efficient planning of the building [23]. Moreover, VR is an effective tool for safety training. With the increasing number of workers coming overseas, it is very important for construction sites to introduce visual-based safety training as an upgrade to the traditional training via demonstrations and media presentations. Recently, VR simulations have been utilized in order to train labor and make them mindful of the project environment. Statistics show that labor trained via VR performs better in identifying risks, with $20 \%$ more than those trained traditionally during the training time. [25]. Moreover, the VR welding training framework assists trainees to learn $23 \%$ quicker than expected and develop better, stronger memories as well as motoric patterns [26]. Furthermore, VR simulation systems for equipment operators are additionally incredible devices for improving both the skill and efficiency of these operators [24].

On the other hand, augmented reality (AR) applications are simplifying some of the construction activities and reducing the cost and time spent on that activity. By combining BIM with AR, different activities can be performed, such as layout marking, excavation, and positioning and placing precast elements. Furthermore, using AR headsets can aid on-site users to visualize the BIM model over the real-world environment, which takes out the need for on-site access to paper or digital drawings and specifications [18]. It was concluded 
that construction laborers utilizing BIM with AR had the option to complete the same task twice as quick as other crew members utilizing the traditional blueprint drawings [27]. Additionally, inspections can also be made simpler, quicker, secure, and less expensive utilizing AR alongside intuitive equipment and associated insight, which can accurately track inspectors' locations as they move around the places of work [28]. Moreover, the ARbased inspection of tunnel construction decreased the overall inspection time by $25 \%$ [29]. With enough mobile device capabilities, photos or virtual notes can likewise be added by the inspectors, which stick to a location and can be shared over multiple devices. Utilizing photogrammetry techniques with imagery data and geo-referencing can create as-built models [18] in the same digital environment with the planned BIM models, making progress monitoring a lot simpler [30].

\section{Material}

As mentioned in Section 1.2, corrosion and disappearance are major issues faced at historical sites. This became significant in preserving architectural heritage. These artifacts have passed through many repair stages and processes in order to repair damages as well as to reconstruct and renovate. It is essential to save a record of these sites to preserve the history of these locations using 3D model technology, as they are present to monitor modifications, predict structural issues, and enable broader tourism to nearly see and visit these sites. The application of virtual environment technologies can reduce a number of these issues. For example, they are reducing the number of visitors who visit historical sites. This can help in preserving historical buildings and reduce possible damage. Aside from that, people do not have to travel long distances to visit famous places. Moreover, these applications allow everyone to explore and experience many sites as if they visited them, thus also saving time and money [31]. Virtual reality technology has helped with the visualization of complicated designs in architecture, since learners can visit simulation rooms to acquaint themselves with the plans, acting as a physical visit in terms of actual architectural designs [32]. Furthermore, it also helps architects and designers with the opportunity to visualize their designs while helping them understand spaces and to avoid possible mistakes before building begins. Lastly, this technology has enabled learners to experience a simulated reality of several complicated designs in one place without traveling [33]. It can be agreed that using virtual and augmented reality is an achievable solution to save heritage sites and, as a further, more advanced step, rebuild demolished historic buildings to the way they were.

\subsection{The 3D Modeling and E-Documentation}

The term E-documentation describes a digital archiving method with an educational functionality based on measured data, online and offline distance learning, and 3D modeling. This expanded digital documentation is a complete sequence of traditional and core digital architectural documents. It can be used for a computer-based architecture, engineering practice, CD- ROM, DVD, online and offline multimedia, and promotional facilities. The aim of e-documentation is to identify precise data structures and metadata on intangible features such as anthropology, economy, history, religion, sociology, psychology science. Then, representing these data in digital form to be Analyzable. For such a system, vast volumes of different data types are compiled and cross-referenced. A historical 3D building or memorial provides a very stable foundation for the creation and distribution of digital data, as is the case with e-documentation (meta-documentation functionality) [34].

According to the Burra Charter [35], the process of preserving cultural heritage consists of three stages: "knowing the meaning, improving policies and operating according to policy" [36]. Moreover, to preserve and document a historic site or building, it is essential to understand the building and collect the information from its physical condition before intervention or action that may cause a change to these heritage sites. Furthermore, several factors are endangering architectural heritage, such as environmental disasters, urban development, demolition, and aging, which from a realistic point of view are not guar- 
anteed for eternity. Therefore, it should ensure accurate documentation of these heritage sites, which could be passed on to future generations as a result of their loss or used for reconstruction purposes if necessary [37]. Many researchers and experts have researched, experimented on, and evaluated the potential of digital technologies in the process of preserving cultural heritage. In fact, cultural heritage specialists, surveyors, and IT and computer experts, especially in developing countries, still have a knowledge gap. Additionally, the rapid development of electronic means has made this method more sophisticated, as cultural heritage specialists must update their expertise to understand the latest useful achievements in preparing conservation plans and necessary policy development [36].

Cultural heritage research has inspired surveyors and experts to suggest new approaches and classifications. Categorization is based on the metric details of the target object and the collection of points and coordinates with or without images. There are three types of documentation techniques: image-based, non-image-based, and hybrid approaches [38].

\subsection{Virtual and Augmented Reality (VREVA) for Documenting Cultural Heritage}

Virtual reality technology (VR) is defined by M. Samadbeik et al. [39] as a simulation of a physical environment in which the perceiver practices their presence digitally. Digital documentation utilization has possibilities for improving the virtual environment where the client experiences a virtual simulated tour within the historic site digitally without being there physically. Moreover, VR also helps visitors select prospective places to visit before they plan their travel. On the other hand, "augmented reality" (AR) technology is a mixture of actual and computer-created data in an interactive real-time perspective that joins virtual objects with realistic or ecological targets [40]. Therefore, AR is used to show the computer-generated details of the historic site, digitally reconstructing a particular moment in history and providing the user with a pleasant adventure.

The purpose of a wide range of technologies for metric cultural heritage documentation approves the multiplicity of suitable selections for an object's documentation. However, the desired accuracy is not guaranteed via a single method, and there are always difficulties as well as issues that limit a technique's potential. In selecting a survey method, the cost, time, complication, and size of the object itself, as well as the approachability and proficiency of the survey team play significant roles. Furthermore, every single method has specific characteristics of its own. However, in most cases, the requirements of a project cannot be met via a single method, and a blend of different techniques is needed in order to achieve the preferred outcome. If the assigned budget allows, this hybrid approach can be the best method to document cultural heritage.

Consequently, in the progression of documenting appreciated objects and sites, it is necessary to study and plan the project requirements and other significant factors in order to guarantee the project's effectiveness. To achieve this result, an expert in the field of cultural heritage can achieve understanding of the project's requirements and be a dependable and trustworthy consultant for surveyors and IT specialists. The outcome of this collaboration has unlimited significance, as it will reduce the risk of time and budget waste and guarantee production usability.

\section{Method}

The ability of BIM to export into different formats can act as the basis for subsequently making it suitable for input into devices supporting the concept of the digital virtual environment. For example, VR and AR can be used in smart mobile devices. Additionally, a number of smart device applications that offer integration with BIM and other technologies have been provided in a number of research projects. For instance, Waugh et al. [41], in order to record construction development, used an environment wherein a web-based augmented panoramic application was presented. Moreover, Park et al. [42] presented an outline for the integration of BIM and AR in the case of clash detection in construction. 
Aside from that, Dunston and Wang [43] provided the complete stages of the facility life cycle via the use of AR applications. Figure 6 shows the outline of the proposed method.

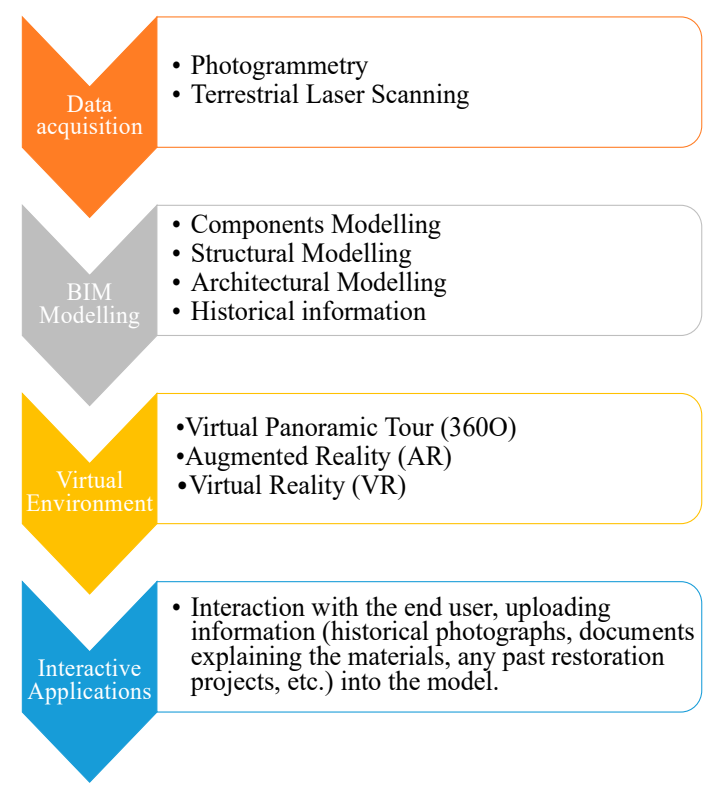

Figure 6. Outline of the method.

Applications (i.e., VR \& VA) help in preserving valuable information regarding historical buildings that have degraded over time [20]. An important aspect that is offered by the applications is the opportunity to recreate destroyed historical context and observe the past. In addition, the old architectural designs can inspire current architecture.

The city's historical architectural design gives the city its uniqueness and importance; it is a strong attraction for tourists. This suggests that the city's traditional architectural designs must be preserved. Similar designs will benefit the city to make it a more beautiful and more significant center for tourists. According to M. Samadbeik et al. [39], VR and AR have improved the efficiency and effectiveness of architectural design, regardless of how complex it is, since VR simplifies the complicated procedures into simpler ones. The applications can benefit both clients and designers, where designs can be displayed to the clients using VR, and then they can have a complete understanding of how the final output will look. The history of damaged or collapsed historical buildings can also be simulated using VR, whereby the building is viewed in different periods of time, and the viewer can relate this with the entire building before it collapsed. Currently, a number of applications are presented in the app market for "mobile BIM". For example, Autodesk A 360, Autodesk 360 glue, Autodesk 360 BIM field, Tekla BIMsight Mobile, BIManywhere, Navigator Pano Review, InfraWorks 360, Graphisoft BIMx, and many more exist. Most of these apps are available on Apple Store and Google Play. The purpose of this section is to express that heritage BIM systems can be integrated with different VR and AR devices, not just by the professionals in the engineering fields, but also by a more extensive community involved in digital reconstructions, cultural heritage preservation, and virtual tourism. Furthermore, as Barazzetti and Banfi [3] stated, these integrations "can be a new opportunity for modeling and understanding cultural heritage". Furthermore, using VR and AR applications to present the heritage buildings and monuments in Historic Jeddah can offer a remote and realistic experience without causing any damage or risk to these heritage sites, in addition to providing visitations to the heritage buildings and monuments that have a sensitive environment or a situation that means it is unsuitable for crowds. 


\subsection{Zainal House Case Study}

Bayt Zainal (Zainal House) is found in a strategic place near to the northern gat of Historic Jeddah (Bab Jaddead, the new gate) and close to Allegiance Square (Figure 7). Furthermore, Zainal House is considered one of Jeddah's historic district's first steel and concrete buildings. Zainal House was constructed in 1920 by the Zainal family. From 1949 to 1957, Zainal House was leased and occupied. Since 1957, Zainal House has been left empty. Lately, the Saudi Commission for Tourism and National Heritage (SCTH) has rented the house. Different proposals were presented to reuse the building. One of these proposals was to reuse Zainal House as the headquarters of the SCTH. From this point of view, as part of early-stage feasibility studies in order to develop Zainal House's outline, providing a 3D interactive digital model by implanting Heritage BIM was the first step, with more focus on creating the Hijazi architectural components.

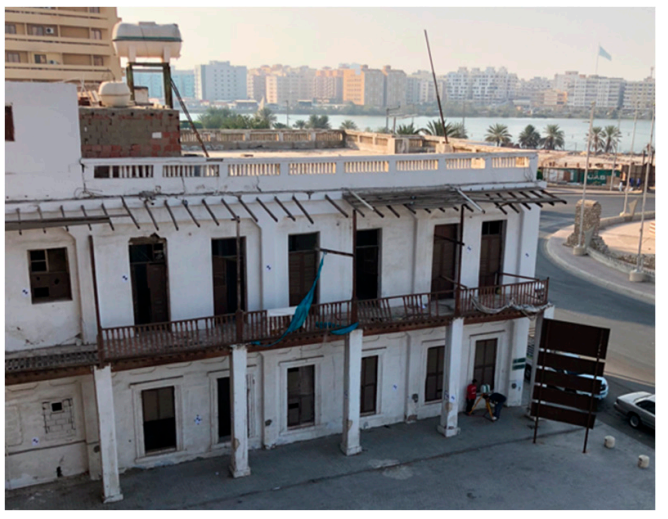

(a)

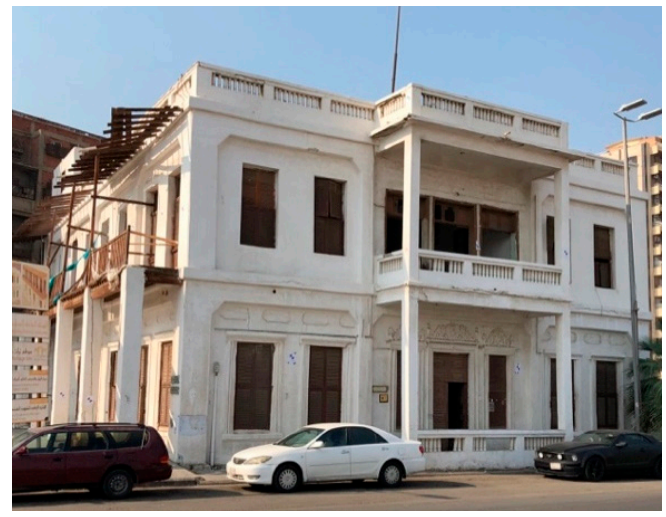

(b)

Figure 7. Bayt Zainal from the (a) east side and (b) north side.

The 3D model was to be based on the 3D point cloud data captured from the site and then supplemented, cross-checked, and provided for modeling. The Zainal House project was divided into four main phases. The first phase started with the traditional surveying and preparing the site for the second phase (i.e., the laser scanning phase). The second phase started with terrestrial laser scanning to scan the building's façades from the outside to the inside. The third phase was to model the building's 3D point cloud to a 3D BIM model and create a 3D object library for the building's elements. The fourth phase was the process of transferring the BIM model to the VR and AR applications. To deal with the 3D BIM model in the VR and AR environment, several mobile applications are available online that can handle this task. The basic concept is to present and show the BIM model on a construction site by providing a shared collaborative environment among the project stakeholders.

Due to considerable developments in technology, the Internet, and cloud services, integrating different levels of users remotely to operate the construction of different projects is possible. This can be conducted via a central 3D model, which can be remotely presented and accessed by the project's stakeholders, evaluating, checking, and managing the project documents via online applications. There is also the benefit of offering the ability to have real-time communication between the stakeholders via e-mail, chat, and video conference notifications [3]. One of the applications for portable devices which was used in this project was Autodesk A360. Moreover, this mobile application is a cloud-based platform that can upload the Revit files to storage. These can be used within a collaborative workspace, and cloud services are available to support the project stakeholders regarding developing the design, visualization, simulation and project information sharing anytime and anywhere.

Autodesk A360 presents several advantages, like visualizing 2D and 3D models in real-time via several predefined perspectives, such as in 3D views (zoom, pan, and rotate) or orthographic plans and sections, as well as tools for mark-up, annotation, and comments. 
In this phase, the eBIM project of Zainal House (the Autodesk Revit file) was exported as a .dwf file format to preserve the elements' properties. These properties included the type, level, and category, among others.

\subsection{Reality Capture: 3D Environment}

The Zainal House project's fieldwork started with locating the ground control points' (GCPs) coordinates. These GCPs provide highly accurate surveying. The reference point number (S177) allocated by the Jeddah municipality was used as the reference point for the Zainal House project.

The second phase initialized with terrestrial laser scanning (TLS) to scan Zainal House's façades from the outside to the inside. This phase took around 14 working days, with Leica C10 laser scanning undertaken by more than 100 scan stations. The outcome of this scanning was a 3D point cloud model of the whole building. The 3D point cloud data processing took around 7 working days to be completed. Furthermore, the laser scanning procedure started by detecting the most accurate position for the scan stations. Defining the coordinates of these positions through the Leica total station depended on the backsight technique (Figure 8). This resulted in the production of net points inside and outside the heritage site. This offered a coordinate map for every single location.
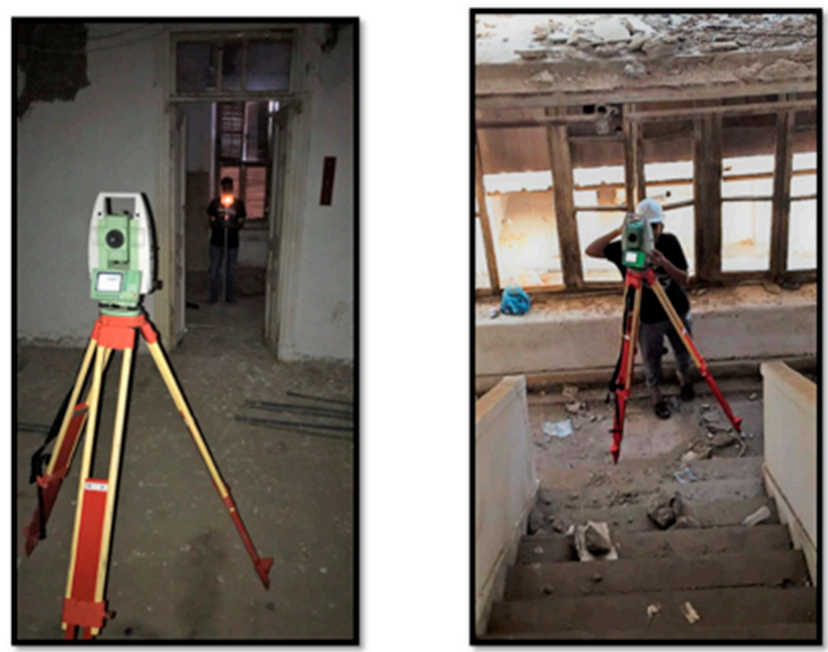

Figure 8. Using the backsight technique with the total station at the site.

The next step was to identify the most suitable spots to place the black and white $(\mathrm{B} / \mathrm{W})$ targets for the TLS method (Figure 9). Moreover, to provide a 3D point cloud model with more accuracy and minimal errors, it was vital to provide at least three accurate $\mathrm{B} / \mathrm{W}$ targets in common between these scan stations. The third step was to scan the Zainal House façades from the outside to the inside. In this step, the overlap between each scan was crucial to cover the whole area of Zainal House. Indeed, the overlapping between these scans was, on average, more than $70 \%$. This could result in a high registration accuracy in case the cloud-to-cloud process was implemented. Each scan station's resolution within a $10-\mathrm{m}$ distance for indoor scanning was $0.07 \mathrm{~m}$, and it was approximately $70 \mathrm{~m}$ for the outdoor scanning. The scanning process took about 2 weeks. 


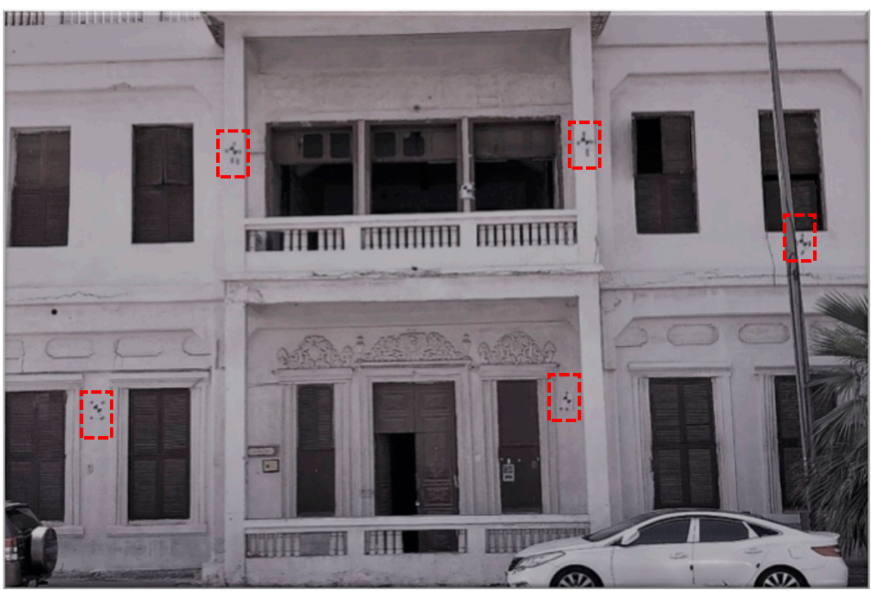

(a)

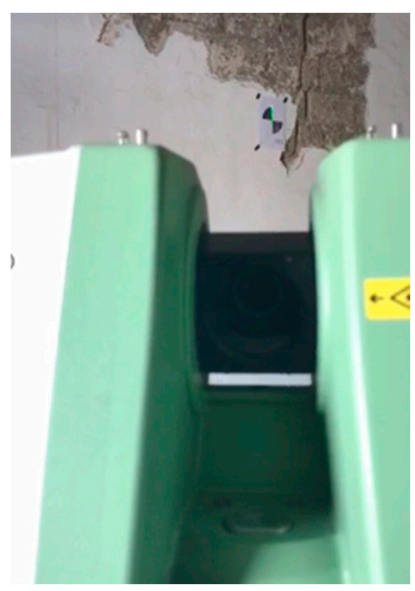

(b)

Figure 9. Utilizing the $\mathrm{B} / \mathrm{W}$ targets on the façades (a) and identifying the target (b).

\section{Point Cloud Data Processing}

The point cloud data processing step was started by inserting the LiDAR data into professional point cloud processing software. For example, Leica Cyclone software was used to create an accurate 3D register model of each scan station for Zainal House. Furthermore, it was crucial to remove all the noise data from the point cloud model during the processing step.

\subsection{D Heritage BIM Model}

The third phase was to introduce the 3D point cloud data into the BIM platform to model the building, creating a 3D component library for the building's elements with the attributes (Figure 10). Several professional modeling applications can handle this point cloud data. For example, one of the most common applications in architecture, engineering, and construction (AEC) is with the Autodesk Revit software, which was used to produce the 3D BIM model of Zainal House due to its speed in terms of modeling time and transferring the point cloud model into "3D BIM" (Figure 11). Aside from that, this software was utilized because of the high level of quality and flexibility offered in producing architecture, engineering, and construction information and documents. Moreover, in this phase, the 3D point cloud was used as the basis for the BIM model, which provided indepth architectural, structural and quantitative values. Three-dimensional orthographic images were implanted and placed on their actual spots on the building façades and the plans, sections, and ground points. The architectural and structural elements such as the columns, doors, windows, and other building elements are illustrated to be part of the object's library. The library parameters measured from the terrestrial laser scanning data were employed in the library's architectural and structural objects before mapping the data to the survey. This is contained in the HBIM plug-in to finalize the building model. This step took 20 working days to model in BIM with LoD 3 (level of detail) over elements like the windows, doors, and plaster, among others. 


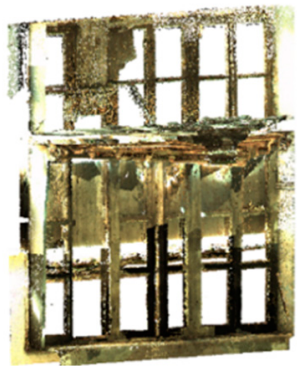

(a)

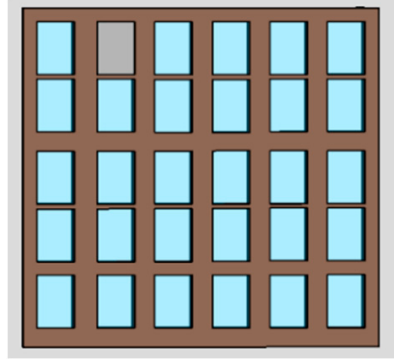

(b)

Figure 10. Creating the object library (window) starting from point cloud (a) to 3D BIM family (b).

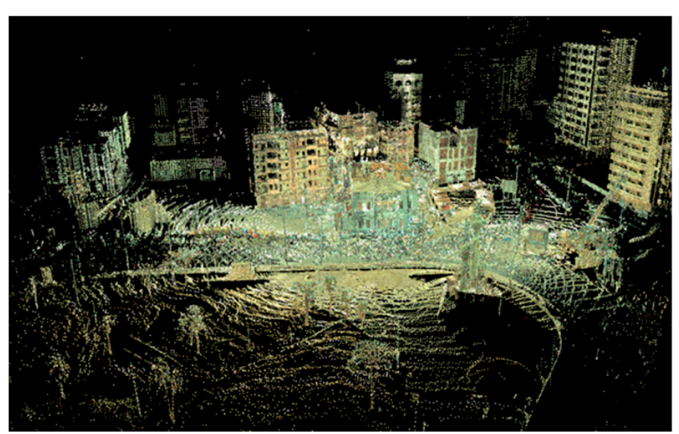

(a)

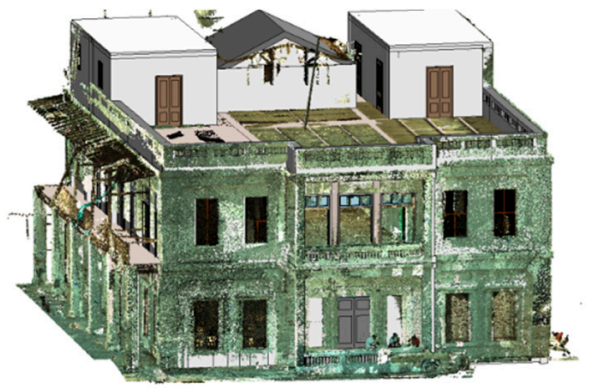

(c)

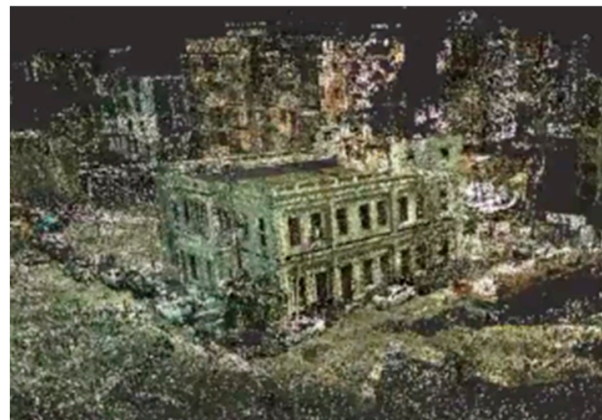

(b)

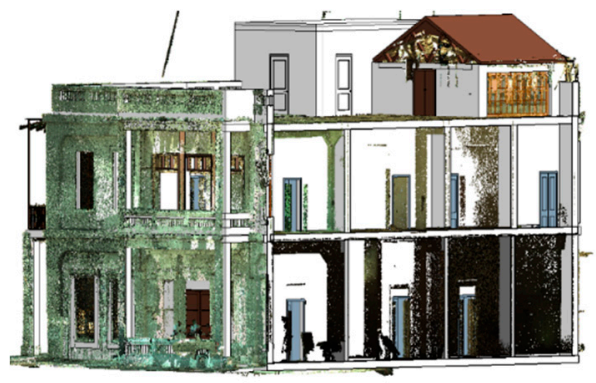

(d)

Figure 11. A 3D point cloud model of the building seen in $(\mathbf{a}, \mathbf{b})$, which is then linked and modeled in Autodesk Revit software as (c,d).

\subsection{From Heritage BIM toward Virtual Panoramic Tours}

Providing a virtual panoramic tour (VPT) usually involves creating rendered $360^{\circ}$ photospheres. Moreover, from the 3D BIM models, a complete virtual tour can be generated. Usually, the panoramic image can be produced through projecting the Earth on a sphere. As a result, the panoramic images are not purely created in a 3D environment; however, the visual effect can be recognized easily. Producing the final output is achieved through laying different image locations that have been captured. According to Barazzetti and Banfi [3], "Virtual navigation is quite fluid also on mobile devices with limited performances", and this is due to the fact that "the output is not a complete 3-D model but only the combination of static images". Furthermore, the linking of several panoramic images will generate a VPT. In this case, the user can visit the different spaces (indoor and outdoor) available at this location.

\section{Results and Discussion}

From Heritage BIM toward Augmented Reality (AR) and Virtual Reality (VR) Technologies

Today, presenting the real world in a digital environment is considered a trendy topic which includes VR, AR, and mixed reality. The integration between BIM models and VR, 
$\mathrm{AR}$, and mixed reality is providing new and significant potential for huge numbers of applications in the architecture, engineering, and construction (AEC) industries [44-47]. The basic concept of using 3D models is to move from the back office to a more dynamic sphere, such as at the construction site, where continuous modifications are always under development. Thus, these purposes need to be developed to deal with technical issues, such as automated localization as well as tracking and alignment for complex sites that need to be significantly updated. Furthermore, the AR applications are based on the 3D model's visualization, and they are to be launched from the printed architecture diagrams, such as the elevations, plans, and sections (Figure 12). Moreover, presenting the 3D architectural and structural models with mechanical, electrical, and plumbing (MEP) services can be achieved via the project presentation boards, which will be employed as markers to visualize the project from different perspectives. Through using a reference object, such as any of the project's floor plans, several 3D contents can be easily reviewed and inspected. Moreover, using AR can be projected as a novel technique in order to understand the whole project. Furthermore, the correlation between BIM with mobile devices and applications based on AR is strong and still developing.

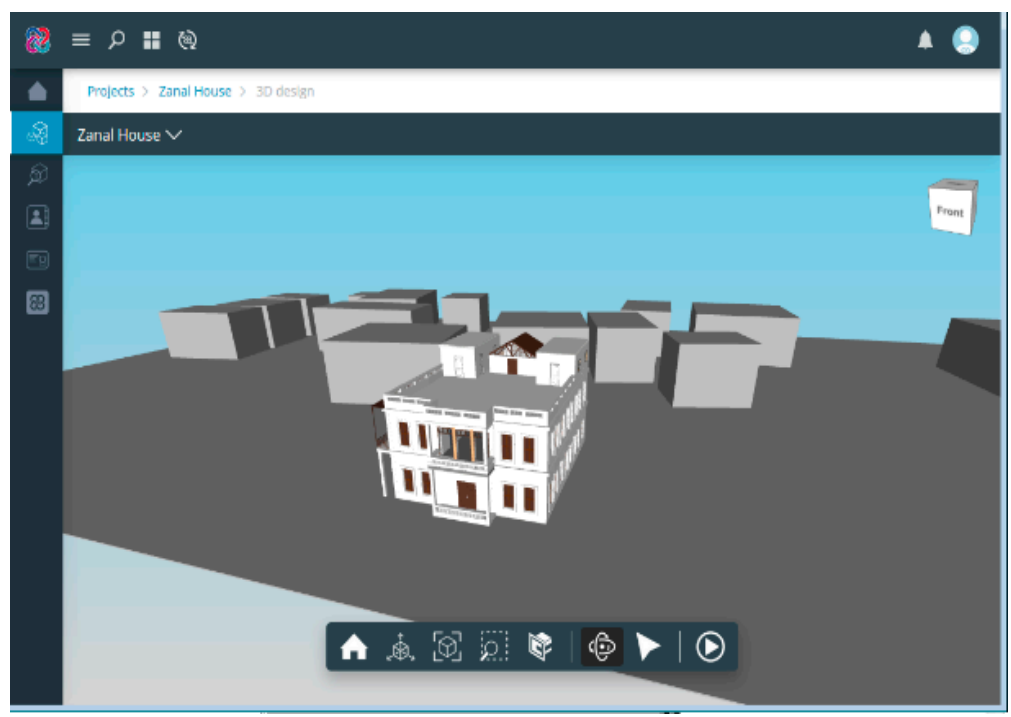

Figure 12. Inserting the model in the BIM server.center.

Using the mobile AR application to produce the engineering information directly from the 3D BIM model can increase the collaboration and sharing of information between the project's stakeholders. Moreover, these AR applications have the ability to use automated geo-localization tools. These tools can be very effective on a construction site. For example, these tools can be used for evaluating the construction's progress, revealing hidden objects, assisting with work, clash detection, and simulating any future situations. Furthermore, AR applications can be very effective in the built heritage sites. This can be due to the stimulation of better collaboration between people (e.g., stakeholders and tourists) and the heritage sites.

Using BIM at heritage sites can be a platform for experts who are most interested in the restoration and preservation of heritage sites. In the case of Zainal Historical House, the Heritage BIM model can be used as an informative and educational tool for cultural tourism (Figure 13). 


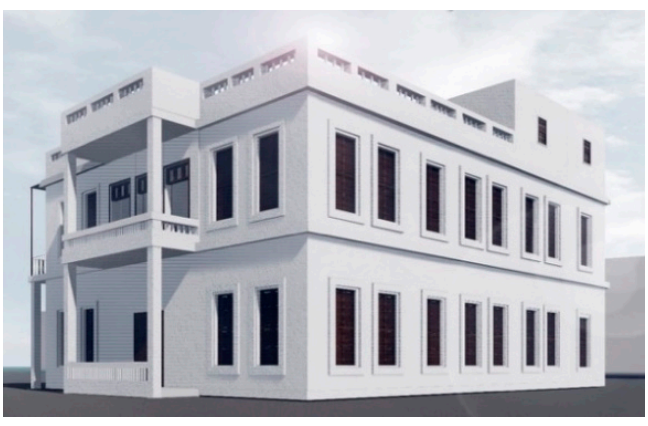

(a)

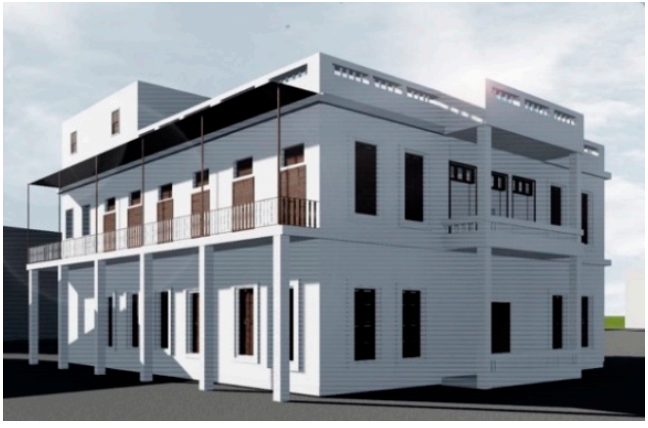

(b)

Figure 13. The 3D eBIM model of Zainal House. (a) shows the north-west elevation, and (b) shows the north-east elevation.

Producing the AR model of Zainal Historical House was achieved via BIMserver.center applications (Figure 14). These applications can work with different formats based on IFC. Moreover, BIMserver.center applications are cloud-based servers which can work on both desktop and mobile devices with the ability to be presented in different head-mounted display (HMD) kits, such as iGlasses.

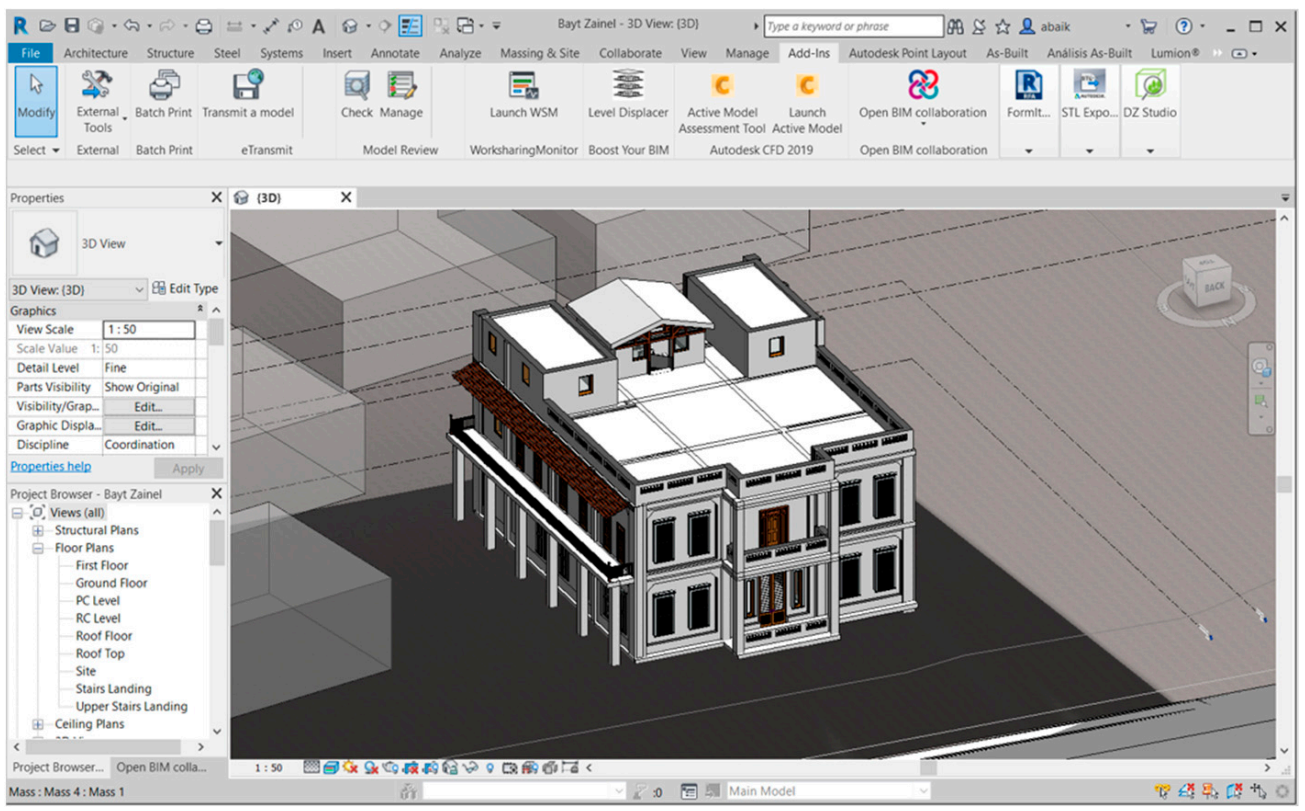

Figure 14. Exporting the 3D BIM model in IFC format.

Additionally, the eBIM of Zainal Historical House was converted from Autodesk Revit format into .fbx format. This step allowed the model to be inserted into several types of modeling software (such as Autodesk 3-D Max). Then, the model could be linked with specific markers. Within Autodesk 3-Ds Max, the model can be exported into AR application formats. This step is important since it can result in a 3D AR model with a limited file size, thus giving it the ability to be transferred to mobile device applications. Lastly, by using the mobile camera to capture the marker (Figure 15), the AR model can be automatically presented. 


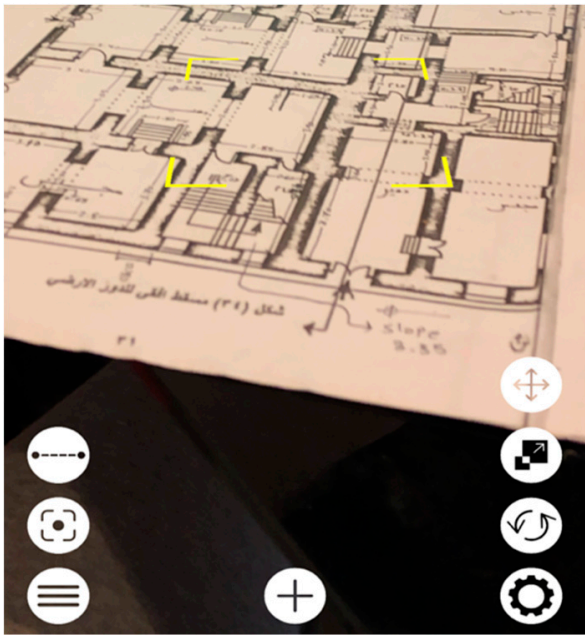

(a)

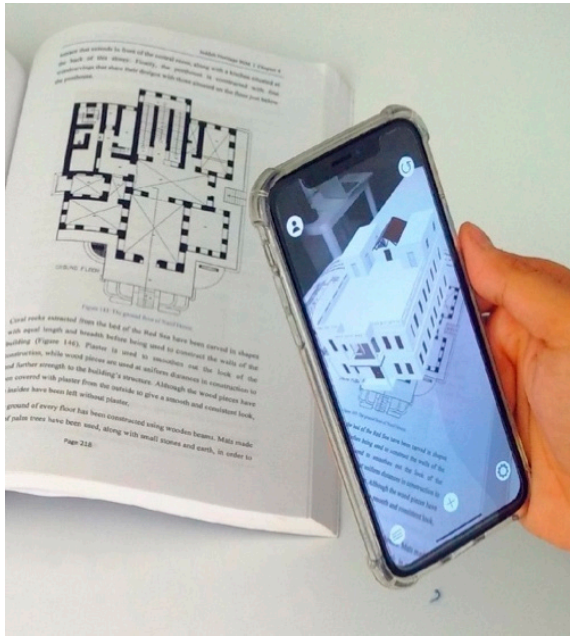

(b)

Figure 15. (a) Scanning the marker and (b), visualizing the model in AR Environment.

\section{Conclusions}

Virtual reality and augmented reality technologies offer unlimited support to the field of architecture. Their application helps in developing potential projects with better performance and fewer resources and saving time [47]. With the use of mobile phone applications which are mostly integrated with a camera, people can experience a virtual reality simulation. Virtual reality technology makes it more applicable in architecture today than previously, when the certain equipment for virtual reality and augmented reality, together with simulation rooms, were costly and unaffordable. Mixed reality, combined VR and AR, results in a better understanding and is more beneficial. They connect anyone anywhere and integrate everything. Preservation of the historical architectural designs is not only crucial for future generations to see them, but it offers a sense of preserving a nation's culture and beliefs [39].

It is essential to preserve cultural heritage and historical sites. The approach to the latest 3D digital scanners affords new ways to preserve these sites digitally and document historical studies by creating geometric and realistic 3D models. A necessary aspect of national identity is cultural and historical heritage. In the collective memory of society, heritage sites, structures, and monuments play an essential role.

The use of a 3D environment seeks to create an active online database website or application shared with the public. The users can be anyone and not only specialists or architects. The users can share not only models or pictures but also stories about any historic building or site. This database attempts to preserve the historical building not only in the form of its appearance or a digital model, but it also seeks to protect the traditions and culture of it. This is a method for preserving the identity of each city.

Funding: This research received no external funding.

Data Availability Statement: No ethical approval was required due to the use of publicly available and/or aggregate secondary data.

Acknowledgments: The author greatly acknowledge research support from King Abdulaziz University.

Conflicts of Interest: The author declares no conflict of interest.

\section{References}

1. Saudi Commission for Tourism and Antiquities (SCTA). The Workshop of Mechanisms to Preserve the Architectural Heritage. 2015. Available online: https:/ / www.youtube.com/watch?v=pultz0hytrY (accessed on 20 January 2017).

2. Paquet, E.; Viktor, H.L. Long-term preservation of 3D cultural heritage data related to architectural sites. In Proceedings of the ISPRS Working Group, Mestre, Venice, Italy, 22-24 August 2005; Volume 4. 
3. Barazzetti, L.; Banfi, F. Historic BIM for mobile VR/AR applications. In Mixed Reality and Gamification for Cultural Heritage; Springer: Berlin/Heidelberg, Germany, 2017; pp. 271-290.

4. Eastman, C.; Teicholz, P.; Sacks, R.; Liston, K. BIM Handbook: A Guide to Building Information Modeling for Owners, Managers, Designers, Engineers and Contractors; Wiley: Hoboken, NJ, USA, 2011.

5. NBIMS-US. About the National BIM Standard-United States. 2015. Available online: http://www.nationalbimstandard.org/ (accessed on 1 July 2021).

6. Murphy, M. Historic Building Information Modelling (HBIM) For Recording and Documenting Classical Architecture in Dublin 1700 to 1830. Ph.D. Thesis, Trinity College Dublin, Dublin, Ireland, 2012.

7. eBIM. Heritage BIM-eBIM. 2015. Available online: http:/ / ebim.co.uk/heritage-bim/ (accessed on 10 April 2016).

8. Baik, A. Heritage Building Information Modelling "HBIM" as a Model of UNESCO's World Heritage Nomination File; University College London: London, UK, 2017.

9. Dirix, E. Former Places of Worship in Dublin: Historic Building Information; University of Leuven: Leuven, Belgium, 2015.

10. Fai, S.; Graham, K.; Duckworth, T.; Wood, N.; Attar, R. Building Information Modelling and Heritage Documentation. In Proceedings of the XXIII CIPA International Symposium, Prague, Czech Republic, 12-16 September 2011.

11. Hichri, N.; Stefani, C.; Luca, L.D.; Veron, P. Review of the «AS-BUILT BIM » Approaches. ISPRS Int. Arch. Photogramm. Remote Sens. Spat. Inf. Sci. 2013, XL-5/W1, 107-112. [CrossRef]

12. Murphy, M.; McGovern, E.; Pavia, S. Historic building information modelling (HBIM). Struct. Surv. 2009, 27, 311-327. [CrossRef]

13. Oreni, D. From 3D Content Models to HBIM for Conservation and Management of Built Heritage. In Computational Science and Its Applications-ICCSA 2013; Springer: Berlin/Heidelberg, Germany, 2013; Volume 7974, pp. 344-357.

14. Penttilä, H.; Rajala, M.; Freese, S. Building Information modelling of modern historic buildings. In Proceedings of the Predicting the Future, 25th eCAADe Konferans1, Frankfurt am Main, Germany, 26-29 September 2007; pp. 607-613.

15. Backes, D.; Thomson, C.; Malki-Ephshtein, L.; Boehm, J. Chadwick GreenBIM: Advancing Operational Understanding of Historical Buildings with BIM to Support Sustainable Use. 2014. Available online: http:/ /www.bso14.org/BSO14_Papers/BSO1 4_Paper_007.pdf (accessed on 1 July 2021).

16. Dore, C.; Murphy, M. Integration of Historic Building Information Modeling (HBIM) and 3D GIS for recording and managing cultural heritage sites. In Proceedings of the VSMM 2012: 18th International Conference on Virtual Systems and Multimedia, Milan, Italy, 2-5 September 2012; pp. 369-376.

17. Massimiliano, P.; Domenica, C.; Alfio, V.S.; Restuccia, A.G.; Papalino, N.M. Scan to BIM for the digital management and representation in 3D GIS environment of cultural heritage site. J. Cult. Herit. 2021, 50, 115-125.

18. Ewart, I.J.; Zuecco, V. Heritage Building Information Modelling (HBIM): A review of published case studies. In Advances in Informatics and Computing in Civil and Construction Engineering; Springer: Berlin/Heidelberg, Germany, 2019 ; pp. 35-41.

19. Brilakis, I.; Pan, Y.; Braun, A.; Borrmann, A. Void-Growing: A Novel Scan-to-BIM Method for Manhattan World Buildings from Point Cloud; Cambridge University: Cambridge, UK, 2021.

20. Alshawabkeh, Y.; Baik, A.; Miky, Y. Integration of Laser Scanner and Photogrammetry for Heritage BIM Enhancement. ISPRS Int. J. Geo-Inf. 2021, 10, 316. [CrossRef]

21. Costantino, D.; Pepe, M.; Restuccia, A.G. Scan-to-HBIM for conservation and preservation of Cultural Heritage building: The case study of San Nicola in Montedoro church (Italy). Appl. Geomat. 2021, 1-15. [CrossRef]

22. Baik, A.H. Heritage Building Information Modelling for Implementing UNESCO Procedures: Challenges, Potentialities, and Issues; Routledge: London, UK, 2020.

23. Thomson, C.; Boehm, J. Automatic Geometry Generation from Point Clouds for BIM. Remote Sens. 2015, 7, 11753-11775. [CrossRef]

24. Ramsey, E. Virtual Wolverhampton: Recreating the Historic City in Virtual Reality. ArchNet-IJAR Int. J. Archit. Res. 2017, 11, 42-57. [CrossRef]

25. Rubio-Tamayo, J.L.; Barrio, M.G.; García, F.G. Immersive environments and virtual reality: Systematic review and advances in communication, interaction and simulation. Multimodal Technol. Interact. 2017, 1, 21. [CrossRef]

26. Salem, O.; Samuel, I.J.; He, S. Bim and Vr/Ar Technologies: From Project Development to Lifecycle Asset Management; ISEC Press: Fargo, ND, USA, 2020; Volume 7.

27. Adascalitei, I. The Influence of Augmented Reality in Construction and Integration into Smart City. Inform. Econ. 2018, 22, 55-67. [CrossRef]

28. Milgram, P.; Takemura, H.; Utsumi, A.; Kishino, F. Augmented reality: A class of displays on the reality-virtuality continuum. In Proceedings of the Telemanipulator and Telepresence Technologies, Boston, MA, USA, 31 October-4 November 1994; Volume 2351, pp. 282-293. [CrossRef]

29. Chi, H.-L.; Kang, S.-C.; Wang, X. Research trends and opportunities of augmented reality applications in architecture, engineering, and construction. Autom. Constr. 2013, 33, 116-122. [CrossRef]

30. Du, J.; Zou, Z.; Shi, Y.; Zhao, D. Zero latency: Real-time synchronization of BIM data in virtual reality for collaborative decision-making. Autom. Constr. 2018, 85, 51-64. [CrossRef]

31. Sacks, R.; Perlman, A.; Barak, R. Construction safety training using immersive virtual reality. Constr. Manag. Econ. 2013, 31, 1005-1017. [CrossRef]

32. Postlethwaite, D. Community college welding program update. Weld. J.-Incl. Weld. Res. Suppl. 2012, 91, 33. 
33. Tatić, D.; Tešić, B. The application of augmented reality technologies for the improvement of occupational safety in an industrial environment. Comput. Ind. 2017, 85. [CrossRef]

34. Styliadis, A.D. Digital documentation of historical buildings with 3D modeling functionality. Autom. Constr. 2007, 16, 498-510. [CrossRef]

35. Icomos, A. The Burra Charter: The Australia ICOMOS Charter for Places of Cultural Significance 2013; Australia ICOMOS Incorporated: Burwood, Australia, 2013.

36. Chu, M.; Matthews, J.; Love, P.E. Integrating mobile building information modelling and augmented reality systems: An experimental study. Autom. Constr. 2018, 85, 305-316. [CrossRef]

37. Zaher, M.; Greenwood, D.; Marzouk, M. Mobile augmented reality applications for construction projects. Constr. Innov. 2018, 18, 152-166. [CrossRef]

38. Albourae, A.T.; Armenakisa, C.; Kyan, M. Architectural heritage visualization using interactive technologies. Int. Arch. Photogramm. Remote Sens. Spat. Inf. Sci. 2017, 42, 7-13. [CrossRef]

39. Samadbeik, M.; Yaaghobi, D.; Bastani, P.; Abhari, S.; Rezaee, R.; Garavand, A. The applications of virtual reality technology in medical groups teaching. J. Adv. Med. Educ. Prof. 2018, 6, 123.

40. Milovanovic, J.; Moreau, G.; Siret, D.; Miguet, F. Virtual and Augmented Reality in Architectural Design and Education. In Proceedings of the 17th International Conference, CAAD Futures 2017, Istanbul, Turkey, 12-14 July 2017.

41. Waugh, L.M.; Rausch, B.; Engram, T.; Aziz, F. Inuvik Super School VR Documentation: Mid-Project Status. In Cold Regions Engineering 2012: Sustainable Infrastructure Development in a Changing Cold Environment; ASCE Publications: Bhopal, India, 2012; pp. 221-230.

42. Park, C.-S.; Lee, D.-Y.; Kwon, O.-S.; Wang, X. A framework for proactive construction defect management using BIM, augmented reality and ontology-based data collection template. Autom. Constr. 2013, 33, 61-71. [CrossRef]

43. Dunston, P.S.; Wang, X. Mixed reality-based visualization interfaces for architecture, engineering, and construction industry. $J$. Constr. Eng. Manag. 2005, 131, 1301-1309. [CrossRef]

44. Dong, S.; Kamat, V.R. SMART: Scalable and modular augmented reality template for rapid development of engineering visualization applications. Vis. Eng. 2013, 1, 1. [CrossRef]

45. Wang, X.; Truijens, M.; Hou, L.; Wang, Y.; Zhou, Y. Integrating Augmented Reality with Building Information Modeling: Onsite construction process controlling for liquefied natural gas industry. Autom. Constr. 2014, 40, 96-105. [CrossRef]

46. Wang, X.; Truijens, M.; Hou, L.; Wang, Y. Application of collaborative mobile system in ar-based visualization, data storage and manipulation. In Proceedings of the International Conference on Cooperative Design, Visualization and Engineering, Seattle, WA, USA, 14-17 September 2013; pp. 221-226.

47. Shen, Z.; Jiang, L.; Grosskopf, K.; Berryman, C. Creating 3D web-based game environment using BIM models for virtual on-site visiting of building HVAC systems. In Construction Research Congress; ASCE: Reston, VA, USA, 2012; pp. 1212-1221. 